\title{
Nutrition status of children in Nepal: Analysis from the findings of Nepal Demographic Health Survey 2016
}

\author{
Ridesh Pokharel ${ }^{1}$, BPH; Bibhor Pokharel ${ }^{2}$, BPH; Rajan Bhusal ${ }^{1}$, BPH; Deepika Chapagain ${ }^{1}$, BPH \\ ${ }^{1}$ Manmohan Memorial Institute of Health Sciences, Kathmandu, Nepal \\ ${ }^{2}$ National Open College, Lalitpur, Nepal
}

Corresponding author

Ridesh Pokharel, BPH

Email: ridesh46@gmail.com

Received 24 Jul 2019

Accepted 13 Nov 2019

\begin{abstract}
Introduction

Nutrition is simply the process of intake of food which is required according to the body need. A well balanced food with regular physical activity is a foundation for a good health. Some effects in health such as reduced immunity, increased susceptibility to disease, poor physical and mental development and reduction in productive capacity can be seen as a result of poor nutrition. The indicators of nutrition are stunting, wasting, underweight and overweight among the children.
\end{abstract}

\section{Methods}

The 2016 Nepal Demographic Health Survey (NDHS) measured the height and weight of eligible children under age 5 in sample households. Weight measurements were taken from lightweight SECA infant scales with a digital display (model no. SECA 878U), designed and supplied by the United Nations Children's Fund (UNICEF). Height was measured with a measuring board (Shorr Boards $\left.{ }^{\circledR}\right)$. Recumbent length was measured for children younger than age 24 months, and standing height was measured for older children.

\section{Results}

Overall, $36 \%$ of children under age 5 were stunted, with $12 \%$ being severely stunted (too short for their age); $10 \%$ were wasted, with $2 \%$ severely wasted (too thin for their height); and $27 \%$ were underweight, with $5 \%$ severely underweight (too thin for their age), while around $1 \%$ of the children were overweight (heavy for their height).

\section{Conclusion}

The different indicators of nutritional status among children such as stunting, wasting and underweight are decreasing. The national program and effective contribution from several nongovernmental agencies is the main reason for the improvement in nutritious status.

Keywords: Children, Nutrition, Stunted, Wasted

\section{Introduction}

Nutrition is simply the process of intake of food which is required according to the body need. A well balanced food with regular physical activity is a foundation for a good health. Some effects in health such as reduced immunity, increased susceptibility to disease, poor physical and mental development and reduction in productive capacity can be seen as a result of poor nutrition ${ }^{1}$. Breastfeeding is a traditional method by which a newly born baby takes as a nutritious food which is carried out from the centuries. For the first six months of life breast 
feeding is only food or drink that all babies need. As the age increases breastfeeding is not sufficient to fulfill the body requirement so right amount of protein, carbohydrate, fat, minerals and fluids should be included in the diet. Even the mother who breastfeed their child have a health benefit compared to who do not feed their child ${ }^{21}$. Every year about 20 million babies are underweight during birth. It is predicted that all forms of malnutrition may cost about US\$ 3.5 trillion per year². Globally, stunting has fall from $11.6 \%$ in 2000 to $9.7 \%$ in 2016 among children of under-five year. The indicators of nutrition are stunting, wasting, underweight and overweight among the children. The intake of food in required quantity of several kinds, status of mother, health services determines the nutrition status of children. Several studies have concluded that the nutritional status of children correlates with school absenteeism and performance in the study.

Over $70 \%$ of world malnourished children are from member states of South-East Asia Region. Likewise, these states are facing the problem "double burden of malnutrition". The multisector approach in relevant sectors such as education, agriculture, fisheries, transport, food processing, economy, media and politics can contribute for the improvement in nutrition. People should be encouraged to feed diverse food to their child ${ }^{4}$.

Food security is also one of the concerned issues for the intake of food which directly relates with the nutrition status of children. Only $39 \%$ of food security is in rural households compared to urban households (54\%). The people of lowest wealth quintile $(39 \%)$ of province $6(18 \%)$ are facing the problems of severe food security ${ }^{5}$.

\section{Methods}

The 2016 NDHS measured the height and weight of eligible children under age 5 in sample households. Weight measurements were taken from lightweight SECA infant scales with a digital display (model no. SECA 878U), designed and supplied by the United Nations Children's Fund (UNICEF). Height was measured with a measuring board (Shorr Boards ${ }^{\circledR}$ ). Recumbent length was measured for children younger than age 24 months, and standing height was measured for older children. Children's height/length, weight, and age data were used to calculate three indices: height-for-age, weight-for-height, and weight-forage. Each one provided different information about growth and body composition and was helpful for assessing nutritional status. As indicated in the first blue box, stunting, or low height-for-age, is a sign of chronic undernutrition that reflects failure to receive adequate nutrition over a long period. Stunting can also be affected by recurrent and chronic illness. Wasting, or low weight for height, is a measure of acute undernutrition and represents the failure to receive adequate nutrition in the period immediately before the survey. Wasting may result from inadequate food intake or from a recent episode of illness causing weight loss. The opposite of wasting is overweight (high weightfor-height), a measure of overnutrition. Weightfor-age is a composite index of weight-for-height and height-for-age. Both acute (wasting) and chronic (stunting) occur as an indicator of overall undernutrition.

Stunting (assessed via height-for-age) Heightfor-age is a measure of linear growth retardation and cumulative growth deficits. Children whose height-for-age Z-score is below minus two standard deviations (-2 SD) from the median of the reference population are considered short for their age (stunted), or chronically undernourished. Children who are below minus three standard deviations (-3 SD) are considered severely stunted ${ }^{6}$. Sample: Children under age 5.

Wasting (assessed via weight-for-height) The weight-for-height index measures body mass in relation to body height or length and describes current nutritional status. Children whose Z-score is below minus two standard deviations (-2 SD) from the median of the reference population are considered thin (wasted), or acutely undernourished. Children whose weight-for-height Z-score is below minus three standard deviations (-3 SD) from the median of the reference population are considered severely wasted ${ }^{6}$. Sample: Children under age 5 .

Underweight (assessed via weight-for-age) Weightfor-age is a composite index of height-for-age and weight-for-height. It takes into account both acute and chronic undernutrition. Children whose weight-for-age Z-score is below minus two standard deviations (-2 SD) from the median of the reference population are classified as underweight. Children whose weight-for-age Z-score is below minus three standard deviations (-3 SD) from the median are considered severely underweight ${ }^{6}$. Sample: Children under age 5. 
Overweight (assessed via weight-for-height) Children whose weight-for-height Z-score is more than 2 standard deviations (+2 SD) above the median of the reference population are considered overweight ${ }^{6}$. Sample: Children under age 5

The means of the z-scores for height-for-age, weight-for-height, and weight-for-age are also calculated as summary statistics representing the nutritional status of children in a population. These mean scores Nutrition of Children and Adults 225 describe the nutritional status of the entire population of children without the use of a cutoff point. A mean Z-score of less than 0 (that is, a negative mean value for stunting, wasting, or underweight) suggests a downward shift in the entire sample population's nutritional status relative to the reference population. The lower the mean $z$-scores are from 0 , the higher is the prevalence of undernutrition. Similarly, the values above zero indicate over nutrition.

\section{Data Collection}

A total of 2,491 children under age 5 were eligible for height and weight measurements from the subsample households. The analysis for anthropometric indices (height-for age, weight-for height, and weight-for-age) included the complete and valid data (valid dates of birth and valid measures of both height and weight) for $97 \%$ of the measured children.

\section{Results}

Overall, $36 \%$ of children under age 5 were stunted, with $12 \%$ being severely stunted (too short for their age); $10 \%$ were wasted, with $2 \%$ severely wasted (too thin for their height); and $27 \%$ were underweight, with $5 \%$ severely underweight (too thin for their age), while around $1 \%$ of the children were overweight (heavy for their height).

The prevalence of stunting and underweight increases with age of the children, peaking at age 24-35 months, while wasting is more prevalent among children younger than age 2 . Almost half of the children reported to be very small at birth are stunted (49\%) and underweight (45\%). Wasting is also common among children who were born smaller. In contrast, only one-third (34\%) of the children reported to be average or larger at birth are stunted, and only $24 \%$ are underweight. Children had higher levels of stunting (45\%), wasting (15\%), and underweight (43\%) among thin mothers compared with those having a normal body mass index (36\% stunted, 10\% wasted, and $27 \%$ underweight).

Mountain zone has the highest proportion of children who are stunted (47\%), while the proportion of wasting and underweight is highest in terai (12\% and 33\%, respectively). Province 6 has the highest proportion of stunted children (55\%) while Province 3 and Province 4 have the lowest proportion of stunted children (29\% each). A higher proportion of children born to mothers with no education are undernourished compared with children whose mothers have an SLC and higher level of education (stunting: $46 \%$ versus $23 \%$, wasting: $13 \%$ versus $8 \%$, and underweight: $37 \%$ versus $16 \%$ ). Stunting is relatively high among children from the lowest wealth quintile (49\%) compared with the highest wealth quintile (17\%) Higher percentage of children is malnourished from severely food insecure households (46\% stunted, and $35 \%$ underweight) compared with children from food secure households (29\% stunted and $22 \%$ underweight).

\section{Discussion}

The prevalence of stunting and of underweight among children under age 5 have markedly decreased, from $57 \%$ to $36 \%$, and from $42 \%$ to $27 \%$, respectively, in the last 20 years (1996-2016). This indicates stunting in children declined by $14 \%$ between 2001 and 2006, declined by an additional 16\% between 2006 and 2011, and dropped by $12 \%$ between 2011 and 2016. A similar downward trend is observed for underweight children. However, in the same time period, changes in wasting were minimal ${ }^{5,7-9}$. The study done in children of Lalitpur city revealed $10 \%$ of underweight and $8.3 \%$ of stunted children. The percentage of underweight $(16.9 \%)$ and stunted (12.2\%) girls was more than that of boys ${ }^{11}$. The study of rural Nepal Kavre and Dolakha district showed 17 (7.0\%) were wasted, in height for age analysis, 97 (39.9\%) were stunted and in weight for age assessment, 46 (18.9\%) were underweight ${ }^{3}$. The study done Dhanusha central Terai of Nepal also showed positive association between mother's education and nutritional status $(p=0.004$ for underweight and $p=0.002$ for stunting) $)^{3}$. The stunting prevalence was found higher among the mother engaged in the service (59.3\%) compared with business(57.3\%) and agriculture $(50.3 \%)^{14}$ physical growth as well as development, productive life and academic performance. The national figures for stunting, 
underweight and wasting in under five years children in Nepal stands at $41 \%, 29 \%$ and $11 \%$, respectively according to NDHS 2011. However, the magnitude of this problem in hilly areas of Nepal is not well understood.Objectives: The objective of this study was to find the nutritional status of 6 to 59 months of children and its associated factors. Materials and Methods: A cross-sectional, population-based study design has been used for this study. The study population was 6 to 59 months children who were permanent or temporary residents of the study area. The respondent was the mother of the under 5 year child. A total $10 \%(n=1353$.

The Sustainable Development Goal (SDGs) aimed to reduce stunting by $15 \%$, wasting by $4 \%$, underweight by $10 \%$ and low birth weight (LBWs) by less than or equal to $1.4 \%$ by 2030 . Aligning with the multi-sector nutrition plan and current global initiatives, family welfare division - nutrition section has developed strategies and plans for improving maternal infant and young child nutrition assisted by experts from the nutrition technical committee. Nutrition programs implemented by FWD nutrition section (19932018) are growth monitoring and counseling and prevention and control of iron deficiency anemia (IDA); prevention, control and treatment of vitamin A deficiency (VAD); Prevention of iodine deficiency disorders (IDD); control of parasitic infestation by deworming; mandatory flour fortification in large roller mills; and maternal, infant and young children nutrition (MIYCN) program as nationwide programs. The scale-up programs are comprehensive nutrition specific interventions, integrated management of acute malnutrition (IMAM), micronutrient powder (MNP) distribution linked with infant and young child feeding(IYCF), school health and nutrition program, Vitamin A supplementation to address the low coverage in 6-11month olds and multisector nutrition plan (MSNP) ${ }^{14}$.

The findings of NHDS 2016 is similar with the study done in 2011 which showed similar findings children residing in mountain ecological belt, mother with no education, severe household security for food and family with lowest wealth quintile. The nutrition program of the country is reached effectively up to the community level. The female community health volunteers(FCHVS) are key person in the community level to promote nutritional to mothers and children. The increased knowledge and economic status is also the reason being improving the nutritious status among the children. Moreover, several projects running by NGOs/INGOs, in the country also contributes for the nutritional status to improve for the time. The current federal system can play a significant role in the improvement of nutritional status among the children. With the establishment of health section in the municipality and rural municipality, stakeholders and health personnel can prioritize the required area of improvement and act accordingly to their plan for the improvement.

\section{Conclusion}

The indicators of nutrition stunting, wasting, and overweight are in the decreasing trend as shown by the past Nepal Demographic Health Survey reports. It is further supported by study conducted by different institution and researcher. The indicators also proved the effectiveness of nutrition program from the center to periphery level. Different intervention programs from INGOs/NGOs are the supporting actors for the improvement in these indicators.

\section{References}

1. WHO | Nutrition. WHO [Internet]. 2017; Available from: https://www.who.int/topics/ nutrition/en/

2. Breastfeeding | Health and Social Services. Available from: https://www.hss.gov.nt.ca/ en/services/breastfeeding

3. 2018 Global Nutrition Report reveals malnutrition is unacceptably high and affects every country in the world, but there is also an unprecedented opportunity to end it. Available from: https://www.unicef.org/ press-releases/2018-global-nutrition-reportreveals-malnutrition-unacceptably-highand-affects

4. World Health Organization, Regional situation. SEARO. 2017; Available from: http://www.searo.who.int/entity/nutrition/ topics/regional_situation/en/

5. Ministry of Health, Nepal; New ERA; and ICF. 2017. Nepal Demographic and Health Survey 2016. Kathmandu, Nepal: Ministry of Health, Nepal. 
6. Blössner, Monika, De Onis, Mercedes \& PrüssÜstün, Annette. (2005)|. Malnutrition : quantifying the health impact at national and local levels / Monika Blössner and Mercedes de Onis. World Health Organization. https:// apps.who.int/iris/handle/10665/43120

7. Ministry of Health and Population (MOHP) [Nepal], New ERA, and ICF International Inc. 2012. Nepal Demographic and Health Survey 2011. Kathmandu, Nepal: Ministry of Health and Population, New ERA, and ICF International, Calverton, Maryland.

8. Ministry of Health and Population (MOHP) [Nepal], New ERA, and Macro International Inc. 2007. Nepal Demographic and Health Survey 2006. Kathmandu, Nepal: Ministry of Health and Population, New ERA, and Macro International Inc.

9. Pradhan, Ajit, Ram Hari Aryal, Gokarna Regmi, Bharat Ban, and Pavalavalli Govindasamy. 1997. Nepal FamilyHealth Survey 1996. Kathmandu, Nepal and Calverton, Maryland: Ministry of Health [Nepal], New ERA, and Macro International Inc.
10. Ministry of Health [Nepal], New ERA, and ORC Macro. 2002. Nepal Demographic and Health Survey 2001. Calverton, Maryland, USA: Family Health Division, Ministry of Health; New ERA; and ORC Macro.

11. Chataut J, Khanal K. Assessment of nutritional status of children under five years of age in rural Nepal. Kathmandu Univ Med J 2016;53(1):73-7.

12. Paudel S, Pradhan PMS, Limbu NPM, Shrestha SM, Pandeya P, Regmi B. Aryal B. Nutrition status of young children in periphery of Lalitpur Sub-Metropolitan city in Nepal. JCMS Nepal. 2017;13(3):330-

13. Sah N. Determinants of Child Malnutrition in Nepal: A Case Analysis from Dhanusha, Central Terai of Nepal. J Nepal Health Res Counc. 2004;2(2):50-4.

14. Dhungana GP. Nutritional Status and the Associated Factors in Under Five Years Children of Lamjung, Gorkha and Tanahun Districts of Nepal. Nepal J Stat. 2017;1:15-8. 